\title{
Children at Risk: A Study of the Psychosocial Impact of HIV on Orphans and other Vulnerable Children in Benin
}

\author{
Lise Rosendal Østergaard* and Dan W. Meyrowitsch**
}

\begin{abstract}
This paper describes the effect of parental HIV on the life of children in Benin. A total of 2,043 children aged from 10 to 16 were surveyed on health, diet, violence, school attendance and psychosocial state. The results indicate that, while Beninese children who have had a parent living with HIV are not necessarily subjected to different economic and material conditions than those who have not, they do experience a much greater lack of psychosocial support. In contrast to children whose parents are not known to have HIV, these affected children are less prone to general illness $(\mathrm{OR}=0.69,95$ per cent $\mathrm{CI} 0.55-0.86)$. However, when they are sick, HIV-affected children are significantly more likely to undertake self-treatment $(\mathrm{OR}=1.38$; 95 per cent $\mathrm{CI} 1.04-1.86)$ and more likely to work $(\mathrm{OR}=1.65$, 95 per cent CI 1.04-2.60). They are also offered fewer meals than unaffected children $(\mathrm{OR}=1.94 ; 95$ per cent $\mathrm{CI} 1.52-2.47)$. With respect to psychosocial factors, the data suggest that children who have had a parent with HIV have significantly higher levels of psychological distress than those who have not. Governments and civil society organisations need to address not only the material deprivation, especially hunger, of children thus affected by HIV, but also their need for social services.
\end{abstract}

\section{Résumé}

Ce document décrit l'effet sur les enfants des parents atteints du VIH au Bénin. L'étude a été faite sur un total de 2043 enfants âgés de 10 à 16 ans par rapport à leur santé, leur régime alimentaire, la violence, leur présence aux cours et leur

* ENRECA Health - The Danish Research Network for International Health, University of Copenhagen. Email: liro@sund.ku.dk.

** Department of Health Services Research, Institute of Public Health, University of Copenhagen. 
état psychosocial. Les résultats montrent que même si les enfants Béninois qui vivent avec un ou des parents atteints du VIH ne sont pas nécessairement assujettis à des conditions économiques et matérielles pires que celles des autres enfants, ils sont tout de même sujets à une absence d'assistance psychosociale. Contrairement aux enfants dont les parents ne sont pas reconnus comme étant atteints du VIH, ces enfants sont moins disposés à souffrir des pathologies courantes ( $\mathrm{OR}=0,69,95$ per cent $\mathrm{CI} 0.55-0.86)$. Cependant, il a été noté que ces enfants concernés, une fois malades, semblent beaucoup plus disposés à se traiter eux-mêmes $(\mathrm{OR}=1,38 ; 95$ per cent $\mathrm{CI}$ 1.04-1.86). Ils sont aussi plus disposés à travailler $(\mathrm{OR}=1,65,95$ per cent $\mathrm{CI} 1,04-2,60)$. Il a été également constaté qu'on leur offre moins de repas que les enfants non-concernés $(\mathrm{OR}=1,94 ; 95$ per cent $\mathrm{CI}$ 1,52-2,47). En ce qui concerne les facteurs psychosociaux, les données montrent que les enfants avec un ou des parents atteints du VIH ont un niveau de détresse psychosociale beaucoup plus élevé que ceux des autres enfants. Les gouvernements et les organisations de la société civile doivent confronter non seulement la privation matérielle, notamment la faim dont les enfants concernés font l'objet, mais également satisfaire leurs besoins en services sociaux.

\section{Introduction}

In the beginning of the HIV epidemic, the international community increasingly responded to HIV as the emergency situation it was. Improved access to effective antiretroviral therapy now makes it possible to look beyond issues of survival, prevention and treatment, and start addressing issues of care and support for people affected by HIV. One group that has come more into focus is children of people living with HIV. The situation of children in the low-income countries that are hardest hit by HIV has been described as a 'rising tide of orphans' (Gosh and Kaplipeni 2004), referring to the fact that the number of children orphaned by HIV will not peak in the foreseeable future. Due to HIV, the overall gains in child survival have fallen, and the total number of orphans due to HIV is estimated to have grown from 11.5 to 15 million between 2001 and 2003 (UNICEF 2004a). If not for the HIV pandemic, the number of orphaned children would have declined globally. Most of the children affected by HIV live in sub-Saharan Africa (UNAIDS 2007), and while there are many other diseases that take a high toll on family well-being there, they are socially more acceptable and do not bear the stigma associated with HIV. Such stigma not only 'infects the infected' but also marks their immediate relatives, including children (Brown 2001; Campbell 2005). From a child's perspective, HIV progresses through several stages infection, illness and, if untreated, death of one or both parents. When a parent can no longer work or when people start staying away from the home, the child starts to feel the impact of HIV with the growing prospect of sorrow and grief. 
The consequences of HIV are often unevenly distributed and can have a strong gender bias; for instance, a girl will often be removed from school to care for an ailing parent while her brother continues with his studies. Although there are only few empirical studies on the psychological impact of HIV on children in the developing world, a study of children's reactions to bereavement and their adjustment difficulties in rural Uganda has shown that losing a parent to HIV leads to higher levels of permanent psychological distress, as expressed through anxiety and depression, than losing a parent to other causes (Atwine et al. 2005). These findings are consistent with those from similar studies in sub-Saharan Africa (Adato et al. 2005; Nyambedha et al. 2003; Guest 2003; Foster and Williamson 2000).

In addition to the social and psychological consequences of becoming an orphan, a recent study of female adolescent orphans in urban Zimbabwe indicates a possible association between orphan status and increased risk of, for example, HIV or unwanted pregnancy (Birdthistle et al. 2008). It has increasingly become clear that African governments and the international community have failed to protect orphans and provide them with decent opportunities. To do so, however, it is important to understand the living conditions and coping mechanisms of children affected by HIV.

While there is a growing focus on the impact of HIV on children in the eastern and southern parts of sub-Saharan Africa, the situation of affected children in West Africa is poorly represented in the academic literature. Furthermore, research on children affected by HIV in countries with concentrated epidemics has been limited. Existing research on affected children has largely emphasised economic deprivation, rather than possible psychosocial consequences (Birdthistle 2004; Stein 2003). The main objective of the present study has been to assess whether children affected by HIV are experiencing more psychosocial distress than other children, and whether they are subject to negative differential treatment in terms of self-reported health status, diet, exposure to violence, or education.

\section{Methodology}

\section{Context, Study Area and Selection of Participants}

This study was carried out in Benin over a period of six months in 2005 in all 12 administrative departments. ${ }^{1}$ Benin has a population of approximately 6.6 million people and a rich diversity of ethnic and linguistic groups, with the Fon, the Adja and the Yoruba as the most dominant. Approximately 31 per cent of the people call themselves Catholic, 24 per cent Muslim, 19 per cent Protestant and 17 per cent animist, with the rest referring to themselves as 
belonging to another or no religion (INSAE 2001). Northern Benin is predominantly Muslim, while the Christian populations are concentrated in the southern and central regions. It should be noted, however, that the majority of the population practises Vodun (voodoo) in combination with another religion, and that Vodun plays an important role in official government discourse as well as in private life (Strandbjerg 2008).

Benin has a rather young population, with an estimated 48 per cent of the people being younger than 15 . Although many of these children live a relatively uncomplicated life, a large proportion of them must confront major survival, health, educational and employment challenges. Living in one of the poorest countries in the world - the UNDP ranked Benin 163 out of 177 on its Human Development Index 2007/08 - Beninese children must face many obstacles before they reach adulthood. The child mortality rate is high, at 152 per 1000 live births (UNICEF 2006), and child morbidity is also high, with diarrhoea, acute respiratory infections and malaria as the most severe diseases (INSAE 2002).

Benin has a pluralistic family structure with many polygamous marriages and many children born out of wedlock. While illegitimate children are not necessarily exposed to social stigma, protection of their rights has been regulated by a mix of traditional and colonial law (the Coutumier du Dahomey from 1930). It was only in 2002, after more than 10 years of debate and pressure from women's organisations and external donors, that a new family law, Code de la Famille et des Personnes, was adopted by Parliament. Among other things, this law guarantees basic inheritance rights and a family name to married women and to children, whether born inside or outside a marriage (Boko Nadjo 2004). If one or both parents die, custody of the children will typically be decided by a family council, the family's elders or a divine authority (a Fâ), without involving any legal authorities. Adoption from outside the country is almost nonexistent, and orphans are seldom placed in orphanages (United Nations 1999). Children in Benin have many duties and few officially recognised rights. One fundamental principle is domestic reciprocity, meaning that every child should perform household chores and contribute economically to the household (by working in the fields or engaging in petty trade) in exchange for protection, shelter and food.

Children affected by HIV are not the only children in Benin experiencing hardship and a higher risk of negative outcomes in life than their peers. One especially vulnerable group is known as 'Vodun children' - twins or children born with certain physical marks, who often, especially in northern Benin, become victims of infanticide or abuse (United Nations 1999). Other groups of vulnerable children include les Talibés - boys who are sent to Qur'anic 
schools (Amadou et al. 2001) - and the 'Vidomegon' children who have traditionally been placed as domestic workers in urban households by their families (Kielleand and Tovo 2006). Additionally, Beninese children are at significant risk for trafficking since the country is a main source of child labour to the cocoa plantations of neighbouring countries (UNICEF 2005; Anti-Slavery 2000). Les Talibés and the Vidomegon children live away from their biological parents in often-exploitative situations. The difference between them and children affected by HIV is that children in the latter group have lost or can anticipate the likely loss of at least one parent to a heavily stigmatised, often fatal disease.

Benin is not as hard hit by the pandemic as many of the countries in eastern and southern Africa. New data indicate that its HIV prevalence is estimated to be 1.9 per cent of the adult population (age 15-49), or approximately 62,000 people (UNAIDS 2005, PNLS 2005). The number of Beninese children younger than 18 who have become orphans as a result of HIV was estimated to be as many as 28,000 in 2002 and was projected to reach 50,000 in 2008 (PNLS 2005). In principle, access to life-prolonging antiretroviral therapy is free for every child and adult who has tested positive for HIV. However, not all infected people are tested, so their actual status remains unknown. HIV-related stigma and misconceptions about the transmission of HIV are widespread, often in combination with Vodun beliefs. For instance, in northern Benin, HIV infection is referred to as 'the monkey disease', and many inhabitants are afraid of HIV-positive people and their children.

\section{Study Design and Sampling Framework}

This paper is based upon the results of a survey, which was a part of a larger study that used both qualitative and quantitative approaches. In addition to the survey, the more comprehensive study included 170 focus group discussions with children and 171 with parents and foster parents. These discussions were supplemented by key informant interviews with schoolteachers, NGO representatives, health personnel and other resource people.

The study population was defined as children aged 10-16. The sample included two groups of respondents: a) children with a biological parent who was living with or had died from HIV, and b) children who lived with both their biological parents, neither of whom was known to be infected with HIV.

Children with a parent who is either living with HIV or dead because of HIV are referred to as orphans and vulnerable children (OVCs), and the other children as non-OVCs. This terminology is widely used by international development agencies (UNICEF and Benin 2004; UNICEF 2004b; Banque 
Mondiale 2004) because it offers a practical operational definition, but it is not unproblematic. It loses some of its significance in Benin, where many children live separated from one or both of their biological parents for various other reasons, and where a child's vulnerability is associated less with being an orphan than with not having any family members who can defend the child's interests. Another problematic aspect is the fact that an OVC is defined as being younger than 18 , an age-specific definition that is not particularly germane in a society where childhood ceases when a person marries or has a child, which often happens well before age 18 in Benin. Moreover, in some Beninese languages, including Batambu and Dendi, the word for orphan is also used to designate a child who is simply behaving badly and 'does not respect anybody'. Nevertheless, OVC has been retained as a case definition for this survey because it requires precise definitions to be meaningful, and a concerted effort was made to ensure that the research assistants employed a correct translation of the term in the various local languages used.

The quantitative data were collected using standardised questionnaires with both closed and open-ended questions. Communities were selected from a national list of all registered communities - arrondissements, villages and neighbourhoods - using a random sampling approach. In each chosen community, households with at least one OVC were mapped using communitybased lists, as well as information from local NGOs working with OVCs or HIV and from other relevant health organisations. To identify OVCs, it was necessary to rely on NGOs that assist children affected by HIV; while the actual serostatus of these children and their parents was not known, each of the children thus identified did have a parent who had HIV symptoms or who had died from a disease most likely resulting from HIV. It should be noted that the OVCs chosen through these organisations are likely to be better off than OVCs who are not receiving assistance from them, and that the OVCs studied may therefore not be representative of all children affected by HIV in Benin. A household was defined as a group of related people living together in the same compound. In each of the chosen communities, several households were then randomly selected. In the vast majority of cases, an OVC was matched with a non-OVC of similar age.

Prior to the survey interviews, informed consent for participation was obtained orally from all the selected children and their respective parents or foster parents. Field assistants interviewed each child in the local language and recorded the answers directly on the questionnaire.

The 50 field assistants who collected data were selected on the basis of their academic records, their experience with data collection and their knowledge of relevant local languages and the country's cultural and social 
fabric. A team of senior researchers trained all the field assistants in how to interact with children in an empathetic way that respected each child's right to opt out of the survey at any point, and that arranged follow-up counselling when it was indicated. The field assistants also translated the questionnaires and interview guidelines from French into the local language, giving special consideration to key terms - such as orphan, orphanhood, vulnerability, rights and protection - that might prove difficult to translate exactly. For example, in Fon, one of the country's dominant languages, / Cyэvi/ is used to identify a child with a dead parent, while / tэcyэvi / is used for a child whose mother has died and / nכcyэvi / a child whose father has died.

During a pilot phase, the field assistants systematically tested all of the data collection tools. To ensure consistency in administering the questionnaires, the assistants were divided into groups under the supervision of experienced team leaders.

The field assistants surveyed a total of 2,043 children aged 10-16 years old (1,033 OVCs and 1,010 non-OVCs). They also surveyed the adult head of each household to obtain data on household income (size and main source), assets and religion to help provide a general portrait of each household. Finally, the data were transcribed and then translated back into French.

\section{Variables}

Fifteen dependent dichotomous variables were included in the analysis, covering self-reported aspects of children's health, diet, violence, psychosocial condition and school attendance. The children were asked to answer questions based on their recollection of the previous two weeks, except for the questions about school attendance and graduation. Health indicators included: the presence or absence of general illness, of malaria, of diarrhoea and of stomach pain; self-treatment for general illness; and whether the respondent worked while being sick. Diet indicators included the number of meals available each day, and whether the respondent had been offered enough food in the last two weeks. Violence indicators were whether the child had been beaten by parents and/or foster parents, or by other children in school. Psychosocial indicators included whether the respondents felt discontented with themselves, whether they had negative feelings about themselves, and whether they felt isolated or rejected in school. School attendance indicators were whether the respondent had ever attended school regularly and whether the respondent had left school before graduating. In addition, the adult informants provided data for the household variables, including household assets, household income and the educational background of the parents or other caregivers. These variables were combined with the child's sex and age as covariables in a logistic regression model. 


\section{Data Analysis and Statistics}

Research assistants entered the data under the supervision of senior statisticians. Logistic regression was then used to assess the gross and net associations between each dependent variable and OVC status. First, bivariate associations between OVC status and dependent variables were assessed. Subsequently, stepwise backward regression was used to adjust the significant associations obtained in the bivariate analysis for the effect of the two covariables, sex and age. All analyses used the SPSS software package, version 15.0.

\section{Results}

A total of 2,043 children were surveyed; see Table 1 for a general demographic and household profile of the study population. All the OVCs studied were living with members of their extended families. The male-female ratio for the sample was 1:1.3 for OVCs and 1:1.4 for non-OVCs. A total of 56.5 per cent of the households were characterised as poor, which was defined as having a monthly income of less than 25,000 CFA francs (•37), while 39.3 per cent had no more than one type of household asset, such as a radio, telephone or bicycle. Approximately one third of the households surveyed included more than three OVCs.

The results of the bivariate and multivariate analyses are shown in Tables 2 and 3. In general, the overall response rate for questions related to health, diet, psychosocial condition and school attendance was high (79.5-99.8 per cent), but for questions related to violence the response rate was lower (29.5-42.1 per cent). Comparison of the children who answered the violence questions with those who did not answer them did not, however, reveal any marked differences in the age or sex distribution of the two groups.

The results of the bivariate analyses showed that OVC status was significantly associated with 11 of the 15 dependent variables. Of these, 9 remained significant in the multivariate analysis. Contrasted with non-OVCs, OVCs were less prone to general illness $(\mathrm{OR}=0.69,95$ per cent CI 0.55 $0.86)$ but more prone to stomach pain $(\mathrm{OR}=1.40,95$ per cent $\mathrm{CI} 1.04-1.86)$. The OVCs were significantly more likely to undertake self-treatment $(\mathrm{OR}=1.38,95$ per cent CI 1.11-1.72) and almost twice as likely to work while sick $(\mathrm{OR}=1.65,95$ per cent $\mathrm{CI} 1.04-2.60)$. OVCs were also offered fewer meals than non-OVCs $(\mathrm{OR}=1.94 ; 95$ per cent CI 1.52-2.47) and were twice as likely to indicate that they were not being offered enough food $(\mathrm{OR}=2.42,95$ per cent CI 1.71-3.41). With respect to psychosocial factors, OVCs were four times as likely as non-OVCs to feel discontented ( $\mathrm{OR}=3.94$, 95 per cent CI 2.80-5.54), five times as likely to have negative feelings about themselves $(\mathrm{OR}=5.46,95$ per cent $\mathrm{CI}$ 4.27-6.97) and four times as likely to feel isolated or rejected in school ( $\mathrm{OR}=4.35,95$ per cent $\mathrm{CI} 2.37-8.00)$. 


\section{Table 1: General Characteristics of Respondents and their Households}

\section{Characteristics}

\section{Respondents}

Number (males/females)

$2,043(1179 / 864)$

Mean age (years) (range)

$12.5(10-16)$

\section{Households}

Number of children in urban households (\% of total)

Mean number of individuals in household (range)

Mean number of children in household $<18$ years (range)

$6.1(1-50)$

Mean number of OVCs in household (range)

Number of households with more than 3 OVCs ( $\%$ of total)

$561(34.0 \%)$

Mean number of asset types in household (range) ${ }^{1}$

Number of children living with only $0-1$ asset type in

household ( $\%$ of total)

$782(39.3 \%)$

Number of households with low household income ${ }^{2}$

(\% of total)

$939(56.5 \%)$

Number of households with agriculture as primary source

of income ( $\%$ of total)

\section{Primary Religion in Rousehold (\% of total)}

Catholicism

Animism

Islam

No religion

Other

1. Household assets were defined as radios, bicycles, televisions, refrigerators, motorbikes, cars, land-line telephones and mobile telephones. The figure indicates the total number of different types of such assets.

2. Monthly household income $<25000$ CFA. 


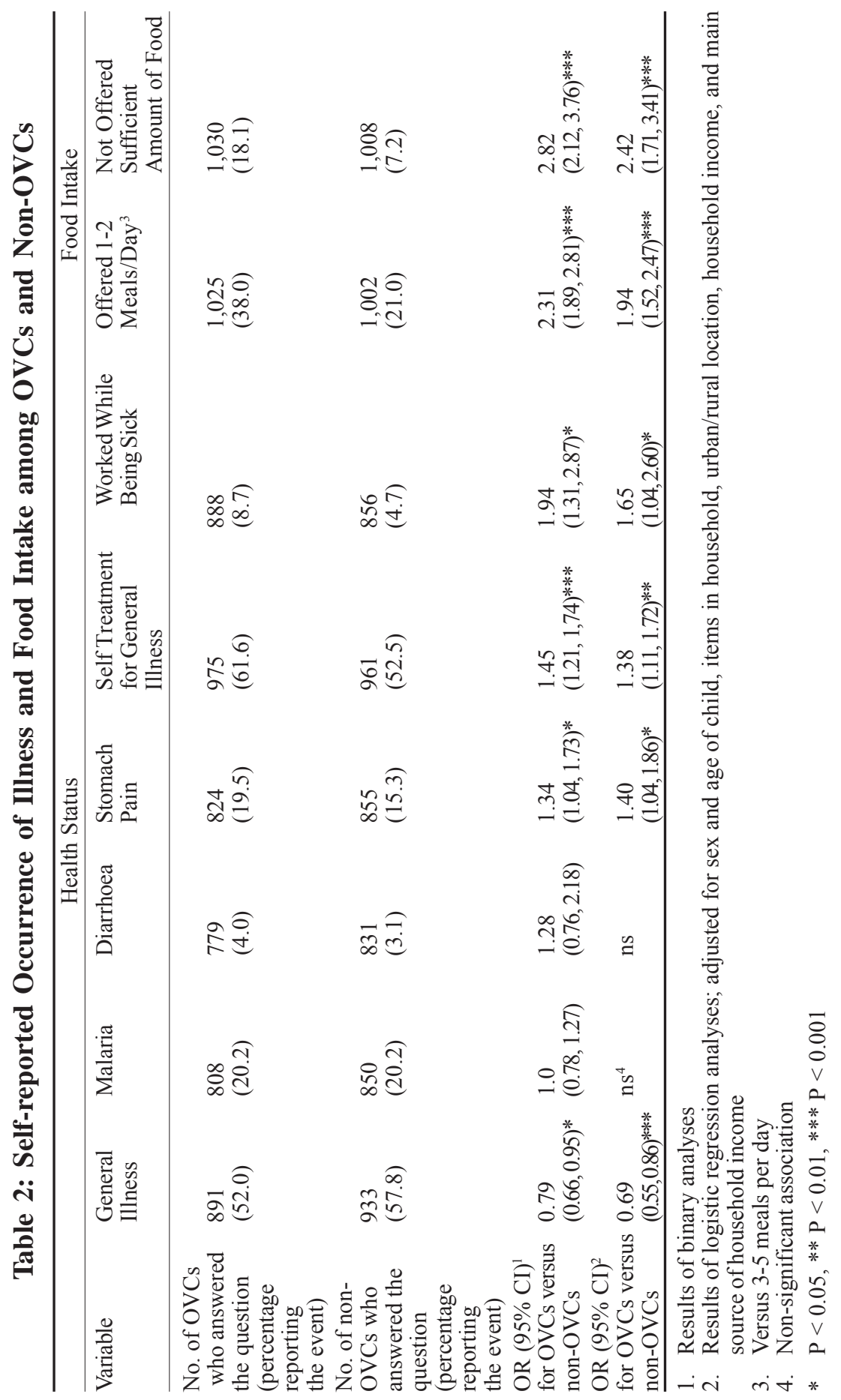




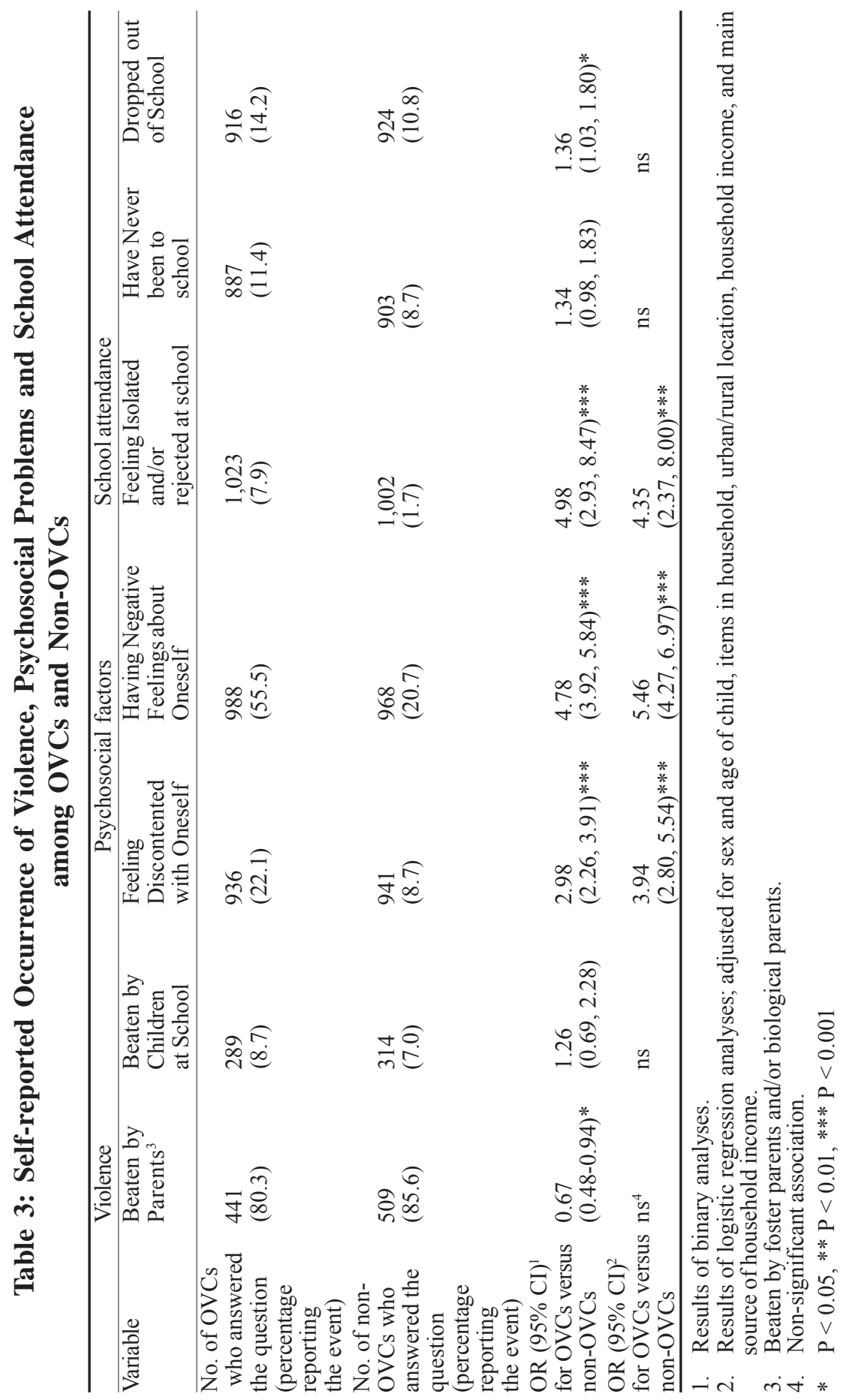




\section{Discussion}

\section{Negative Differential Treatment within a Household}

The findings from this study suggest that, in some respects, orphans and vulnerable children receive less care and attention from their caregivers than other children in the same household. At the same time, however, the results show that the effects of being an OVC are less pronounced than initially expected. For example, OVC school attendance is almost identical to nonOVC attendance, while somewhat surprisingly, OVC status can even predict slightly more positive outcomes, as in the case of general illness and caregiver violence. Nonetheless, OVCs were more likely to eat only one or two meals per day, and they also reported higher levels of dissatisfaction with the amount of food offered. In Benin, children are typically given a small amount of money to buy breakfast on the way to school, and it may be that OVCs are not always given this money and therefore eat less throughout the day. Access to regular meals is associated with intellectual performance and physical development; since the OVCs in this survey reported not receiving sufficient food, their learning abilities and general development have likely been compromised.

Another area where the data indicate strong disadvantages for OVCs is disease status. Considering that OVCs are at much higher risk for being infected with HIV perinatally and therefore for suffering from HIV-related illnesses later in life, it is surprising to find that OVCs are actually less likely to report general illness. It may be that many of the infected children die before the age of ten and therefore are not widely represented in the OVC sample. The data show that when OVCs are feeling sick they are more likely to engage in self-treatment, for example buying drugs at a local market or pharmacy. This finding suggests that OVCs are less likely to be taken to a health clinic or a traditional healer for treatment than non-OVCs. As the study did not specificially investigate levels of morbidity in the two groups, the health consequences of this relative failure to access available services are difficult to assess. However, it does suggest that OVCs are subjected to greater hardship, a conclusion supported by the fact that the OVC cohort was twice as likely to work while sick.

\section{Levels of Psychological Distress Among Orphans and Vulnerable Children}

One of the objectives of this study was to assess the psychosocial impact of $\mathrm{HIV}$ on children. The findings suggest that OVCs have significantly higher levels of psychological distress than non-OVCs, in accordance with findings from previous quantitative and qualitative studies employing other assessment methods (Birdthistle 2004; Atwine et al. 2005; Stein 2003). As indicated by the high proportions of both OVCs and non-OVCs who reported 
being beaten by their caregivers in the previous two weeks, violence against children is endemic in Benin (Kielland and Tovo 2005). Although the data indicates that OVCs are less exposed to violence from their caregivers than non-OVCs, the association does not remain statistically significant after adjusting for the covariables.

The study also showed that Beninese OVCs are more likely to feel discontented with themselves than their peers are, and that they are as much as five times as likely to report that they have a negative perception of themselves, rather than a positive or neutral one. These feelings were just as pronounced when it came to self-perception in a specific social setting, for example school, where OVCs were again five times as likely to feel isolated or rejected. Other studies have found that OVC status is a significant predictor for feeling isolated in school, for example in South Africa, where 97 per cent of children orphaned by HIV reported that they had no close friends (Cluver 2003, as cited in Stein 2003). Thus, although the OVCs in the present study had almost the same school enrolment rates as non-OVCs, their learning opportunities may already have been compromised when they entered school, given that they have eaten less and are less likely to receive treatment when ill than their schoolmates. Psychological distress compounds these initial disadvantages.

\section{Ways Forward: Areas for Future Research and Support}

The results of the present study clearly support the presumption that children affected by HIV are at higher risk for various negative experiences, including not being able to eat when hungry, not being cared for when sick and not feeling social and emotional connections to others. The vulnerability of Beninese OVCs appears to be rooted in the dynamics of stigmatisation and poverty. They suffer a double stigma of being children who are associated as orphans with both bad behaviour (as noted above) and HIV; a widely feared infection. Yet there remains a dearth of comparative research into the similarities and differences between HIV orphans and other orphans. Most existing studies - this one included - compare children orphaned by HIV with non-orphans. It would be useful for future research to assess different kinds of vulnerability among different kinds of orphans.

The findings from this study may reflect the fact that many of the households surveyed were already constrained economically, and that parents who have taken an average of more than three OVCs into their household are already stretching meagre resources and merely choose to prioritise their own children. However, poverty and closeness of blood ties cannot explain all the negative differential treatment these children are subjected to both inside and outside their households. Stigmatisation and prejudice directed 
against people living with HIV also affects their children and places these children in a difficult situation. It cannot be stressed enough that improving the lives of OVCs requires broad-based HIV educational efforts, as well as advocating for the rights of children in affected communities.

Though the OVCs studied have urgent physical needs, particularly for sufficient food, very few of these children receive any government help. Instead, they have all been unsystematically connected to various faith-based organisations and other NGOs. From these NGOs, they typically receive a small amount of food or other allowances, but it is very rare that they are given any kind of psychosocial support addressing the emotional neglect and other negative changes they have experienced during their parents' illnesses.

It seems obvious that Benin requires a new type of OVC support project, one that provides not only material support but psychosocial support as well. Such projects should assess each child's well-being and check up regularly on how they are handling their situations emotionally and psychologically as they grow up. One entry point for this kind of intervention could be schools, which are at present far from being a safe place that can support the passage of OVCs from childhood to adulthood. Another entry point could be the foster families, where regular visits from social workers would support caregivers in providing OVCs with appropriate care and development opportunities. Such interventions should not, however, exclude other categories of vulnerable children, as there are, as mentioned above, several other significant groups of children who live in Benin as de facto social orphans. The importance of inclusiveness is especially important in a low HIV-prevalence country like Benin, where singling out the relatively few children who are orphans as a result of HIV may only contribute to their social isolation.

\section{Study Limitations}

The present study has some overall limitations that chiefly relate to selection bias generated by the sampling procedures, and these potential biases should be considered before generalising the result to apply to Benin as a whole. As previously mentioned, the OVCs surveyed were identified by health sector and NGO staff and may differ from the overall population of OVCs. In addition, the non-OVCs surveyed were selected because they shared a household with an OVC, and they may therefore differ from the population of non-OVCs who live in families without OVCs. Finally, as mentioned above, less than half of the children studied answered the questions on parental and peer violence. This low coverage probably reflects the sensitive nature of the questions, which may have influenced the responses. Questions on sensitive matters such as these can often result in over or underreporting of the phenomena being investigated. 


\section{Conclusion}

Even though access to antiretroviral therapy for both adults and children in Africa has progressed considerably over the past few years, the social impact of the epidemic there is far from over. Many more children in lowincome countries will find their parents becoming sick or dying from HIV in the years to come, and their needs urgently need to be addressed. Although anthropological research has shown that the circulation of children in and out of different households and their residing away from their biological parents is a widespread and well-functioning phenomenon throughout the continent, the situation of OVCs there calls for special attention. This study shows that the current focus on providing these children with financial assistance has left some critical gaps. The children that HIV has made vulnerable do require material help, especially food, but they also require psychosocial support to help them thrive and grow. Governments and NGOs alike have key roles to play in ensuring that these children receive it.

\section{Acknowledgements}

The authors wish to thank the children and their care takers who shared so generously their life stories with us. We would also like to thank our colleagues in Benin who prepared and conducted the field work in Benin as well as Anne Kielland for her valuable comments to the initial report and support over many years.

\section{Note}

1. The study was commissioned by Benin's Ministry of Family Affairs and Social Protection and its National Program Against HIV/AIDS and funded by UNICEF and the World Bank. One of the authors (Lise Rosendal Østergaard) participated in the study as an independent consultant. A number of international NGOs and their local partners participated in the background group that monitored the study.

\section{References}

Adato, M., Kadiyala, S., Roopnaraine, T., Biermayr-Jenzano, P. and Norman, A., 2005, Children in the Shadow of AIDS: Studies of Vulnerable Children and Orphans in Three Provinces in South Africa, International Food Policy Research Institute. Amadou, M. and Sero Koto, S., 2001, Les Talibés au Nord du Bénin enfance malheureuse : un mode de vie choisi, PIED ONG.

Anti-Slavery, 2000, Trafficking of Children Between Benin and Gabon, Submission to United Nations Commission on Human Rights, www.anitslavery.org/archive/ submission/submission2000-Benin.htm. 
Atwine, B., Cantor-Graae, E. and Bajunirwe, F., 2005, 'Psychological Distress Among AIDS Orphans in Rural Uganda', Social Science and Medicine 57 (2005) 555-564. Banque Mondiale, 2004, Boite à outils pour l'ASS: Une boite à outils pour la prise en charge des orphelins et enfants vulnérables (OEV) en Afrique subsaharienne (ASS), 1st Edition, December 2004 www.worldbank.org/ovctoolkit Banque Mondiale, 2001, Les orphelins du SIDA au Bénin: analyse de situation et proposition d'actions, Cotonou, Washington, September 2001.

Barnet, T. and Whiteside, A., 2002, AIDS in the Twenty-First Century: Disease and Globalization, Palgrave Macmillan.

Beegle, C., De Weerdt, J. and Dercon, S., 2005, Orphanhood and the Long-run Impact on Children, World Bank.

Benotsch, E. G., Stevenson, Y., Sitzler, C.A., Kelly, A. J., Makhaye, G., Mathey, E. D., Somlai, A. M., Brown, K. D., Amirkhanian, Y., Fernandezl, I. and Opgenorth, K. M., 2004, 'HIV Prevention in Africa: Programs and Populations Served by NonGovernmental Organizations', Journal of Community Health Vol. 29(4) 319-336.

Birdthistle, I. J., Floyd, S., Machingura, A., Mudziwapasi, N., Gregson, S. and Glynn, J. R., 2008, 'From Affected to Infected? Orphanhood and HIV Risk among Female Adolescents in Urban Zimbabwe' in AIDS, 30 March 2008, 22(6):759-66.

Birdthistle, I., 2004, 'Understanding the Needs of Orphans and Other Children Affected by HIV and AIDS in Africa: State of the Science', working draft, April 2004, prepared by the Support for Analysis and Research in Africa (SARA) project, operated by the Academy for Educational Development for United States Agency for International Development, Washington, D.C.,

Boko Nadjo, G., 2004, 'Le code des personnes et de la famille Béninois', Presentation at NGO Forum, Addis Ababa, (http://www.wildaf-ao.org/fr/IMG/doc/ Boko_Nadjo_FR.doc).

Brown, L., Trujillo, L. and Macintyre, K., 2001, 'Interventions to Reduce HIV/ AIDS Stigma: What Have We Learned?', Horizons Program, Tulane University, http://www.popcouncil.org/pdfs/horizons/litrvwstigdisc.pdf

Campbell, C., Foulis, C. A., Maimane, S. and Sibiya, Z., 2005, 'I Have an Evil Child at My House: Stigma and HIV/AIDS Management in a South African Community', American Journal of Public Health, May 2005, 95:808-815.

Donadje, F. and Soton, A., 2004, 'Genre et VIH/SIDA au Bénin: une synthèse de la collecte de données, Présentation donnée lors de la conférence «Santé de la reproduction au Nord et au Sud, de la connaissance à l'action », Louvain-LaNeuve (Belgium), 17-20 November 2004, www.demo.ucl.ac.be/cq04/.

Foster, G. and Williamson, J., 2000, 'A Review of Current Literature on the Impact of HIV/AIDS on Children in Sub-saharan Africa' in AIDS 2000 (14) S75-S284. Gosh, J. and Kalipeni, E., 2004, 'Rising Tide of AIDS Orphans in Southern Africa' in: Kalipeni, E., Craddock, S., Oppong, J. R. and Gosh, J. (eds.), 2004, HIV and AIDS in Africa: Beyond Epidemiology, Blackwell Publishing.

Guest, E., 2003, Children of AIDS: Africa’s Orphan Crisis, Pluto Press. 
INSAE (L'Institut National de la Statistique et de l'Analyse Economique) and ORC Macro, 2002, Enquête Démographique et de Santé au Bénin 2001, Claverton, Maryland, USA.

Kalipeni, E., Craddock, S., Oppong, J. R. and Gosh, J. (eds.), 2004, HIV and AIDS in Africa: Beyond Epidemiology. Blackwell Publishing.

Kielland, A. and Tovo, M., 2006, Children at Work: Child Labor Practices in Africa, Rienner.

Lazarus, J., Christiansen, C., Østergaard, L. R. and Richey, L. A., 2005, Models for Life: Advancing Antiretroviral Treatment in Sub-Saharan Africa, Current African Issues no 31, Nordic Africa Institute.

Nations Unies, 2005, Progrès accomplis dans la mise en œuvre de la Déclaration sur le VIH/sida: Rapport du Secrétaire Générale. Assemblée Générale, A/59/765.

Nyambedha, E. O., Wandibba, S. and Aagaard-Hansen, S., 2003, 'Changing Patterns of Orphan Care Due to the HIV Epidemic in Western Kenya', Social Science and Medicine 57, 2003, 301-311.

Phiri, S. and Webb, D., 2002, 'The Impact of HIV/AIDS on Orphans and Programme and Policy Responses’ in Giovanni A. C. (ed.) AIDS, Public Policy and Child Well Being, UNICEF-IFR, Florence.

PNLS (Programme national de lutte contre le SIDA), 2005, Etude sur la prise en charges des PVVIH au Bénin, Draft Document, Benin, February 2005.

PNLS (Programme National de Lutte Contre le SIDA), 1998, Le SIDA au Bénin: Epidémiologie, Projections, Conséquences Socio-économiques, Interventions, PNLS / Ministère de la Santé, de la Protection Sociale et de la Condition Féminine / The Futures Group International, Cotonou.

Prywes, M., Coury, D., Fesseha G., Hounsounou, G. and Kielland, A., 2004, ‘Cost of Projects for Orphans and other Vulnerable Children: Case Studies in Eritrea and Benin', Social Protection Discussion Paper Series, No 0414, Social Protection Unit, Human Development Network, The World Bank www.worldbank.org/sp.

République du Bénin, Comité national de lutte contre le SIDA, Ministère de la famille et de la protection sociale et de la solidarité, Ministère de la santé publique, 2004, Conférence nationale sur les orphelins et enfants rendus vulnérables par le VIH/SIDA(OEV): Rapport, Abomey, 17-19 May 2004, Plan Bénin, UNICEF.

République du Bénin, 2005, Analyse de situation des orphelins et enfants vulnérables (OEV), CNLS-UNICEF-Banque Mondiale-CRS Bénin-Plan BéninPPLS-MSP/PNLS-MFPSS.

Stein, J., 2003, Sorrow Makes Children of Us All: A Literature Review on the Psycho-Social Impact of HIV/AIDS on Children, Centre for Social Research Working Paper No. 47. University of Cape Town.

Strandsbjerg, C., 2008, Les sens du pouvoir : Les forces «occultes» à la grâce divine. religion et transformations politiques dans le Bénin contemporain, PhD Thesis, Ecoles des Hautes Etudes et Sciences Sociale, Paris.

UNAIDS (Joint United Nations Programme on HIV/AIDS) and WHO (World Health Organization), 2006, 07 Epidemic Update. 
UNICEF, 2003, Les générations orphelins d'Afrique, http://www.unicef.org/ publications/files/africas_orphans.pdf

UNICEF (United Nations Children's Fund), 2004a, Children on the Brink 2004, A Joint Report of New Orphan Estimates and a Framework for Action, New York: UNICEF, UNAIDS and USAID.

UNICEF (United Nations Children's Fund), 2004b), 'The Framework for the Protection, Care and Support of Orphans and Vulnerable Children Living in a World with HIV/AIDS', http://www.unicef.org/Framework_English.pdf.

UNICEF (United Nations Children's Fund), 2005, 'Benin and Nigeria pledge to fight child traffiking', News Note. http://www.unicef.org/media/media_2709.htlm. UNICEF and La République du Bénin, 2004, Etude sur l'initiative de reformes législatives phase II : Etude nationale du Bénin, September 2004.

UNICEF (United Nations Children's Fund), UNAIDS (Joint United Nations Programme on HIV/AIDS) and USAID (United States Agency for International Development), 2004, Children on the Brink 2004: A Joint Report of New Orphan Estimates and a Framework for Action, July 2004 http:// www.unicef.org/publications/files/cob_layout6-013.pdf

United Nations, 1999, Committee on Rights of the Child Continues Review of Report of Benin, Press Release, HR/CRC/99/28.

Williamson, J., Cox, A. and Johnston, B., 2004, A Framework and Resource Guide: Conducting a Situation Analysis of Orphans and Vulnerable Children Affected by HIV/AIDS, USAID. 